\title{
Endoscopic ultrasound-guided transmural gall- bladder drainage with a lumen-apposing metal stent using an electrocautery enhanced delivery system
}

A 77-year-old woman with multiple comorbidities was referred for symptomatic chronic calculous cholecystitis. She was not a surgical candidate for cholecystectomy and refused percutaneous gallbladder drainage. Endoscopic ultrasound (EUS)-guided transmural gallbladder drainage with a lumen-apposing metal stent (LAMS) using an electrocautery enhanced delivery system was performed ( Video 1).

The echoendoscope was advanced to the duodenal bulb. The gallbladder was accessed with a needle, and contrast injection confirmed the location. A guidewire was coiled within the gallbladder lumen. A 15-mm LAMS with an electrocautery enhanced delivery system was used to dissect a transmural tract into the gallbladder. The stent was deployed with the distal flange in the gallbladder and the proximal flange in the duodenal bulb. Dilation of the stent to $15 \mathrm{~mm}$ was performed using a controlled radial expansion balloon. Following dilation, pus and dark bile were seen draining from the gallbladder ( $\bullet$ Fig. 1).

The patient was discharged home the next day without any abdominal pain. She had no recurrence of abdominal pain at 6-month follow-up.

The use of LAMS with an electrocautery enhanced delivery system minimizes the risks associated with dilation of the transmural tract prior to stent placement, including gallbladder decompression, bile leak, and stent migration [1,2]. EUS-guided transmural gallbladder drainage using LAMS has also been described for internal gallbladder drainage in patients with percutaneous cholecystostomy catheters who are poor candidates for cholecystectomy [3]. EUS-guided transmural gallbladder drainage is safe, feasible, and effective for decompressing the gallbladder in patients who are poor surgical candidates.

\section{Endoscopy_UCTN_Code_TTT_1AS_2AD}

Competing interests: Dr. Kahaleh has received consulting grants from BSC, Pinnacle, and Xlumina, and research grants from FSC, GORE, Cook, Olympus, Maunakea, and Merritt.

\section{Nikhil A. Kumta, Marina Lordello Passos, Gustavo Luis Rodela Silva, Aleksey Novikov, Michel Kahaleh}

Division of Gastroenterology and Hepatology, Weill Cornell Medical College, Cornell University, New York, New York, United States

\section{References}

1 Anderloni A, Buda A, Vieceli $F$ et al. Endoscopic ultrasound-guided transmural stenting for gallbladder drainage in high-risk patients with acute cholecystitis: a systematic review and pooled analysis. Surg Endosc. In press 2016. DOI: 10.1007/s00464-0164894-X

2 Baron TH, Grimm IS, Swanstrom LL. Interventional approaches to gallbladder disease. $\mathrm{N}$ Engl J Med 2015; 373: 357-365

3 Law R, Grimm IS, Stavas JM et al. Conversion of percutaneous cholecystostomy to internal transmural gallbladder drainage using an endoscopic ultrasound-guided, lumenapposing metal stent. Clin Gastroenterol Hepatol 2015; 14: 476-480

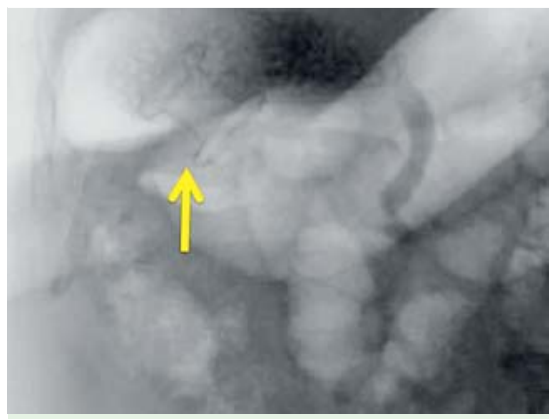

Fig. 1 Fluoroscopic image of a lumen-apposing metal stent (yellow arrow) between the gallbladder and duodenum for endoscopic management of cholecystitis.

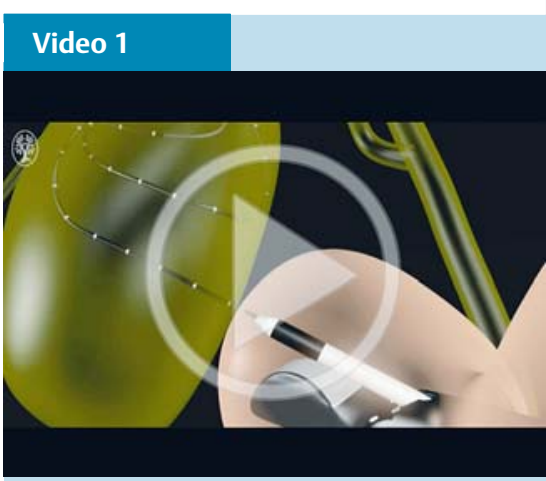

Endoscopic ultrasound-guided transmural gallbladder drainage with a lumen-apposing metal stent using an electrocautery enhanced delivery system.

Bibliography

Dol http://dx.doi.org/

10.1055/s-0042-117634

Endoscopy 2016; 48: E327

(c) Georg Thieme Verlag KG

Stuttgart · New York

ISSN 0013-726X

\section{Corresponding author}

\section{Michel Kahaleh, MD}

Division of Gastroenterology and Hepatology

Weill Cornell Medical College

New York

NY 10021

United States

Fax: +1-646-962-0110

mkahaleh@gmail.com 